تعيين ميزان شيوع آسيبهاى اسكلتى - عضلانى و ارتباط آن با بوسجر كارى در تعمير كاران صنعت مس

$$
\text { معصومه كرمى'، سعيد قانع عز آبادى '، زهره كرمى"، ياسر صحرانورد" }
$$

مقدمه: اختلالات اسكلتى - عضلانى يكى از عوامل شايع آسيبهاى شغلى است كـه بـهـ طـور عمــده در جكيده

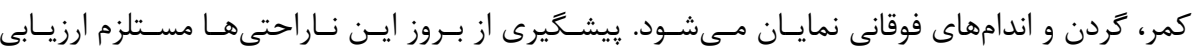

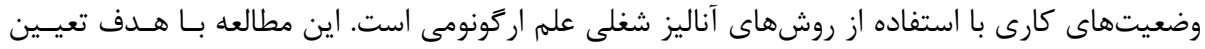

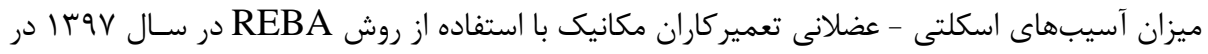
مس سر جشمه انجام شد. روش بر رسى: در اين مطالعه توصيفى- تحليلى، وضعيتهاى انجام كار صه نفر شاغل در شغل تعميـرات مكانيك با استفاده از روش REBA ارزيابى شد. ميزان شيوع اختلالات اسكلتى- عضلانى نيز با استفاده

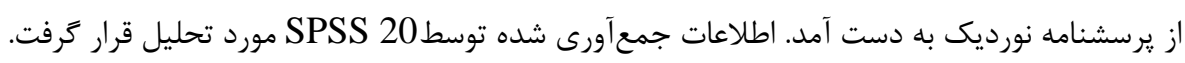

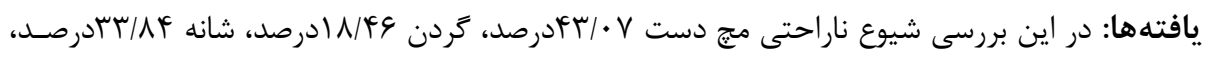

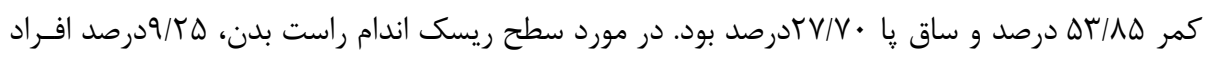

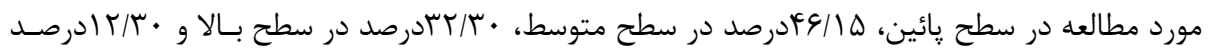

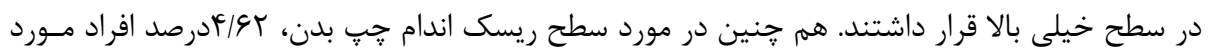
مطالعه در سطح يائين، |\&/\& | خيلى بالا قرار داشتند. نتيجهَّيرى: اين نتايج حاكى از آن بود كه وضعيتهاى كارى افراد مورد مطالعـه نيـاز بــه اصـلاح دارد. آموزش شناخت عوامل خطر بيومكانيك و روشهاى صحيح انجام كار، استفاده از ابزار مناسب و متناسب با فرايند كارى، بهبود و كنترل فاكتورهاى استرسزا و تأثير خذار محيطى بـراى پيشـيشيرى از بـروز ايسن

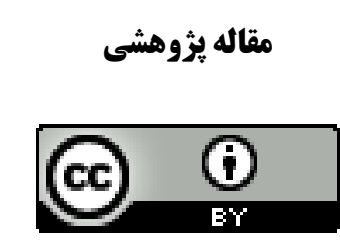

كرمى معصومه، قانع عزآبادى سعيد، كرمى زهره، صحرانورد ياسر. تعيين ميزان شيوع آسيبهاى اسكلتى - عضلانى و ارتباط آن با يوسجر كارى در تعمير كاران صنعت مس. بهداشت

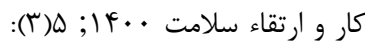
IFr-TQ.

كليد وازهها: ارزيابى ارگونوميكى، وضعيتهاى بدن،تعمير كاران مكانيك، روش REBA 


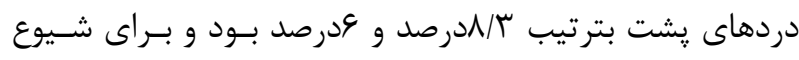

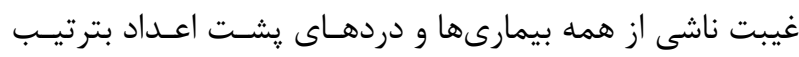

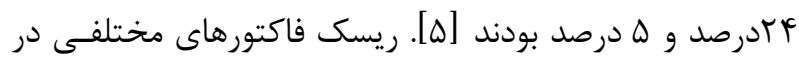

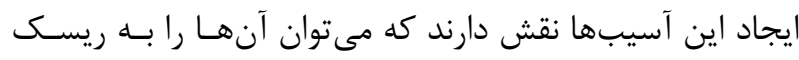

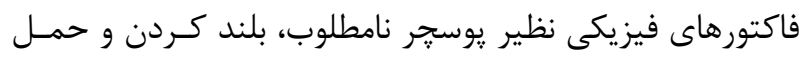

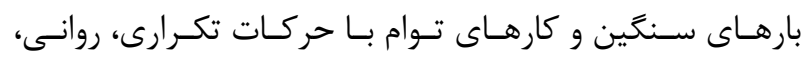

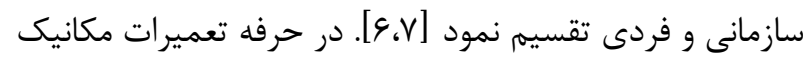

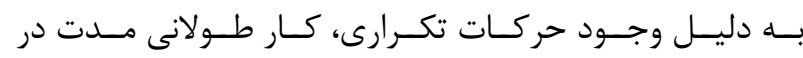
وضعيتهاى ايستاده و وضعيتهاى غلـط كـارى، احتمـال بـروز ناراحتى هاى اسكلتى - عضلانى وجـود دارد بِيشــيرى از بـروز اين ناراحتى ها مستلزم ارزيابى وضعيتهاى بدنى بــا اسـتفاده از

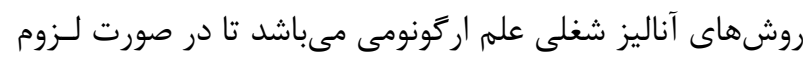

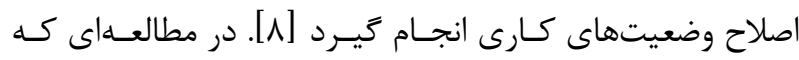
دكتر ميرحسينى و همكاران در شهر اصفهان در بين كتابـداران كتابخانه هاى دانشخاههاى دولتـى انجـام دادنـد، نشـان داد كـهـ

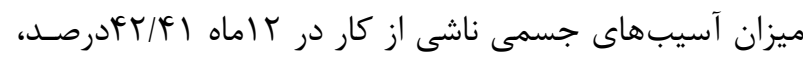

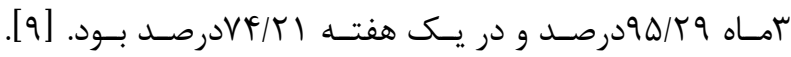
مطالعهاى كه يعقوبى و اسماعيلى در مورد ارزيابى اركونـوميكى وضعيتهاى كار دانشـجويان دندانيزشـكى انجـام دادنـد، نتـايج

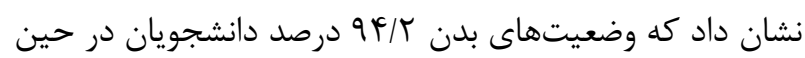
كار در سطح متوسط و بالا بود و نيـاز بــه اصـلاح داشـت [ـ ـ1].

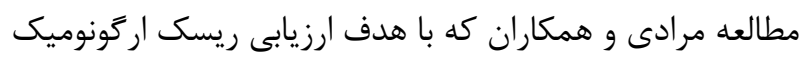

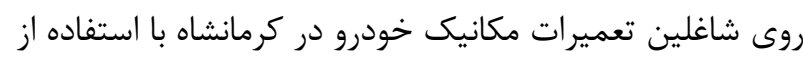

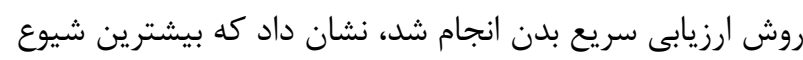

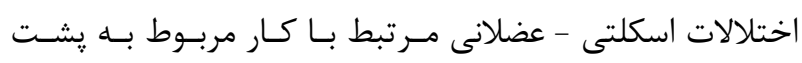
(

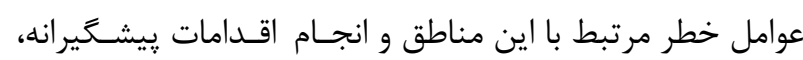

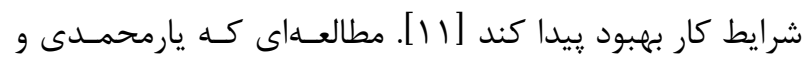

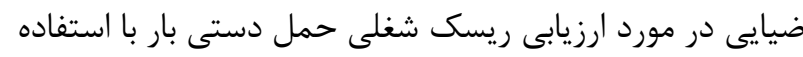

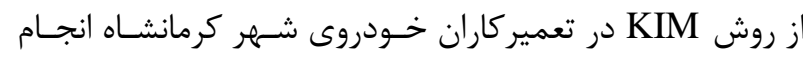
دادند، نتايج نشان داد كه بيشترين ميزان ناراحتى در حين كـار
اختلالات اسكلتى - عضلانى يكى از عوامل شايع آسيبهـاى

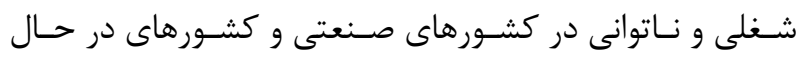

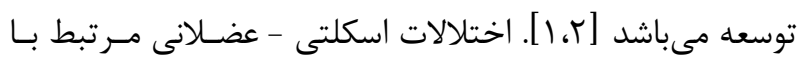
كار معمولاً باعث دركيرى كمر، ستون فقرات كردنى و اندامهاى

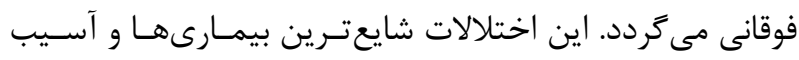

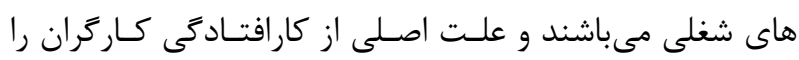

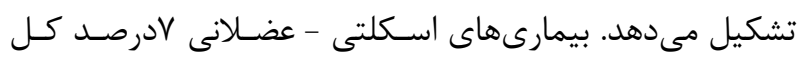

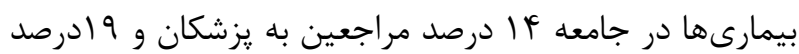

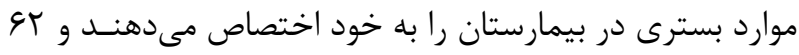
درصد مبتلايان به بيمارىهاى اسكلتى - عضلانى به نوعى دجار

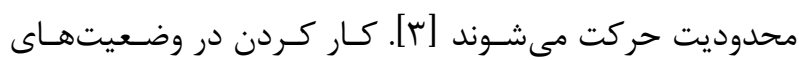
سخت و ناراحت كننده موجـب نـاراحتىهـــى زودكـذر در تمـام اعضاى بدن مىشود و קنان קه فرد در مدتهاى طولانى مدت

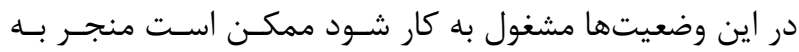
ناراحتى هاى ديخــى در بافت عضـلانى - اسـكلتى يـا اعصـاب محيطى شـده و در نهايـت موجـب از كارافتـادكى او شـود هــم

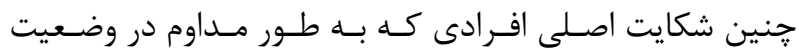

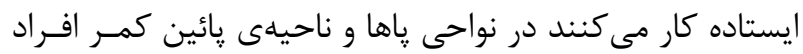
مىباشد [F]. بر קايه تحقيقات انجام شده برخلاف گسترش ابزار مكانيزه و خودكار، اختلالات اسكلتى - عضلانى مـرتبط بـا كـار

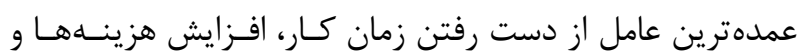

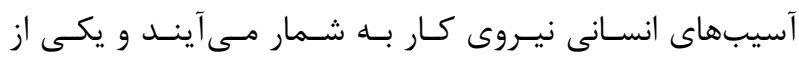

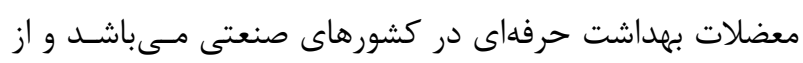

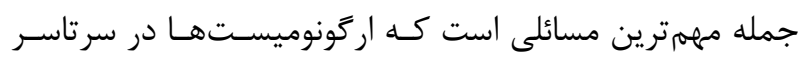

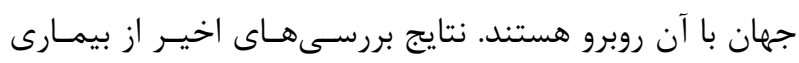

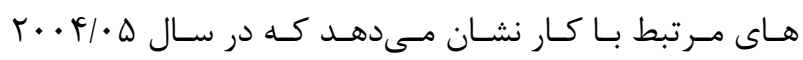

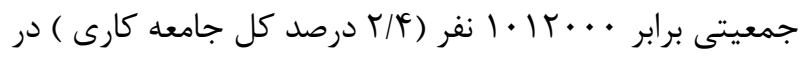

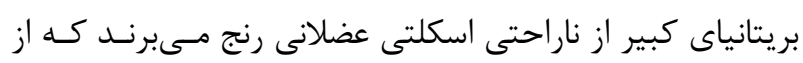

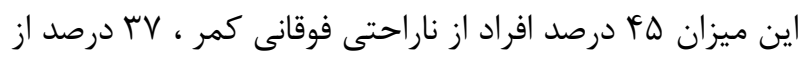

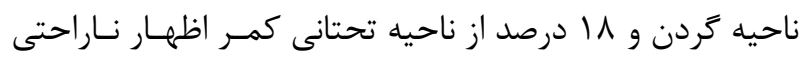

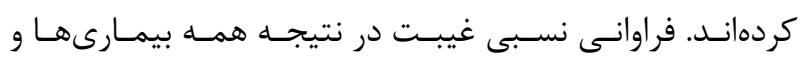




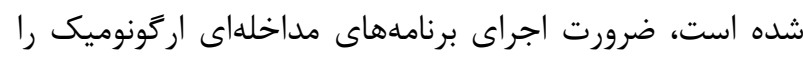

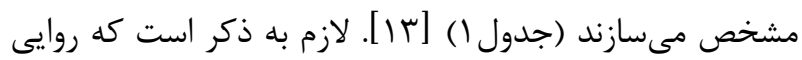
و پايايى روش فوق در يك طرح يزوهشى كه توسط خانم مهناز صارمى در بين دندانيزشكان دانشكاه شاهد انجام شده در ايران

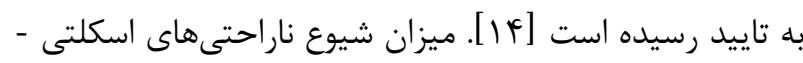

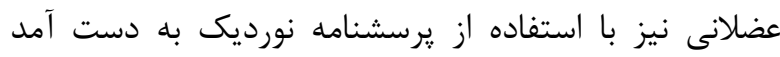

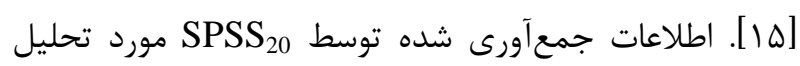

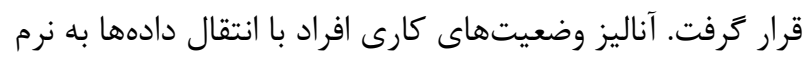
افزار ربا انجام شد. همجنين دادههاى مربوط به شيوع ناراحتى

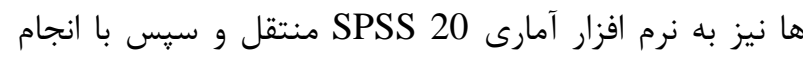
آزمونهاى آمارى كاى اسكوئر و تى مستقل رابطه بين شيوع

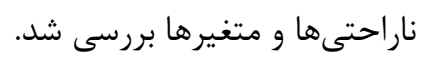

\section{يافتهها}

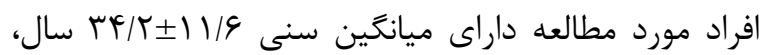

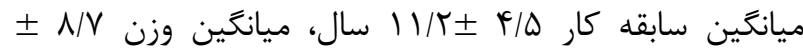

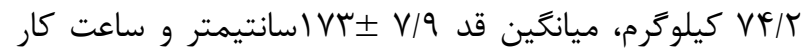
روزانه 9 ساعت بود. ارتباط بين ميانخين سن و سابقه كار افراد مورد يزوهش با ناراحتى هاى اسكلتى - عضلانى معنادار نبود. ارتباط بين ميانكَين ساعات كار در روز با ناراحتىهاى كمر و

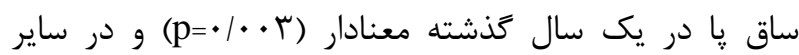

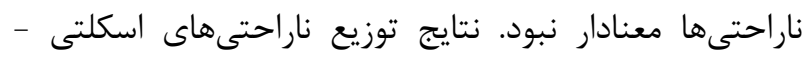

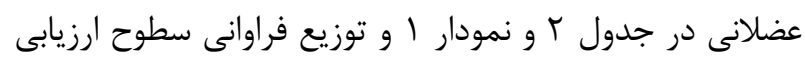

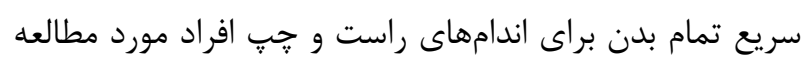

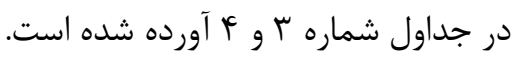

در نواحى يشت و كمر بود و ضرورت دارد مداخلات اركونوميكى

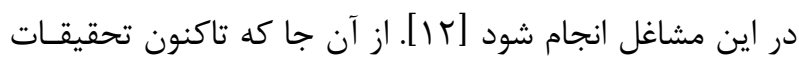

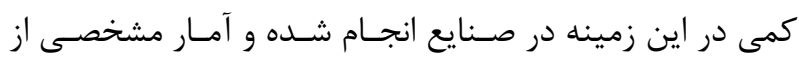

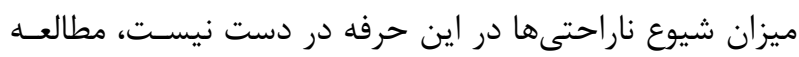

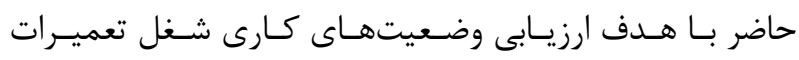

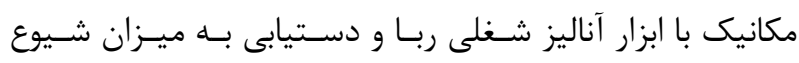

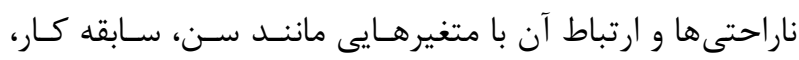
ميانكَين سابقه كارى و وضعيتهاى بدنى انجام شد.

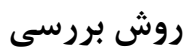

در اين مطالعه توصيفى- تحليلى از نوع مقطعى به روش بردي سرشمارى و با مراجعه حضورى وضعيتهاى كارى 40 تعمير كار مكانيك در واحدهاى مختلف كارخانه مس سر جشمه در سال Vوبا توسط جك ليست ارزيابى سريع تمام بدن REBA (Rapid Entire Body Assessment (REBA)) شد. اين روش، روشى مناسب براى ارزيابى مشاغلى است كه در

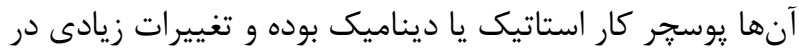
يوسجر و وضعيت انجام كار روى مىدهد. در اين روش كه به وسيله مك آتامنى و هيخَت (Mc Atamney \& Hignett) ارائه شده است، ابتدا يوسجر يا فعاليتى كه بايد ارزيابى شود انتخاب مى كردد، سيس با استفاده از دياترامهاى طراحى شده، يوسجر

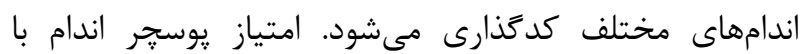

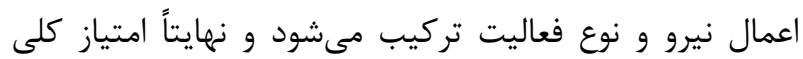

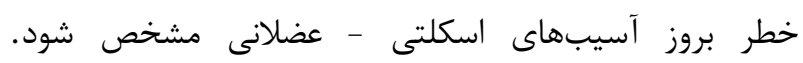
سطحهاى اولويت اقدامهاى اصلاحى كه در اين روش ييشنهاد

جدول ا: سطح خطر و اولويت اقدامهاى اصلاحى در روش REBA

\begin{tabular}{|c|c|c|c|}
\hline ضرورت اقدام و زمان آن & اقدامات اصطح اولويت & سطح خطر & امتياز نهايى REBA \\
\hline ضرورى نيست & - & قابل حشم يوشى & 1 \\
\hline شايد ضرورى باشد & 1 & 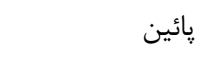 & $r-r$ \\
\hline 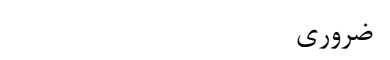 & r & متوسط & $r-\gamma$ \\
\hline ضرورى (هر جه زودتر) & r & بالا & $\Lambda-1$. \\
\hline ضرورى (آنى) & r & بسيار بالا & $11-10$ \\
\hline
\end{tabular}


در بررسى نتايج، بيشترين ناراحتى مربوط به كمر تعمير كاران بود. ارتباط معنادارى بين ميانگين سن و سابقه كار با ناراحتىهاى اسكلتى - عضلانى وجود نداشت. ارتباط بين ميانگين ساعات كار در روز با ناراحتىهاى كمر و مج دست در يك سال حذشته معنادار ولى در ساير نواحى بدن معنادار نبود. هم جنين رابطه معنادارى بين ناراحتىهاى كمر با ميانگين نمرات نهايى ارزيابى سريع تمام بدن براى اندامهاى راست و جِ نتايج نشان داد كه 1 درصد افراد مورد يثوهش از ناراحتى مج دست، 9 (ادرصد ناراحتى گردن، سזردص ناراحتى شانه، ץFرصد ناراحتى كمر و rrدرصد ناراحتى ساق یا در يكسال كذشته رنج بردهاند كه بيشترين ناراحتى مربوط به كمر افراد تعمير كار بود كه با نتايج مطالعات حجازى و همكاران در مورد ناحيه كمردر كارگران كورههاى آجر يزى كناباد همخوانى دارد [lV] و با نتايج مطالعاتى كه در مورد افراد شاغل در حرفه دندانيزشكى فعاليت دارند انجام شده است اختلاف وجود داشته كه با توجه به نوع فعاليت كارى اين اختلاف قابل بيشبينى بود [ [1]. با نتايج مطالعه مرادى و همكاران كه روى شاغلين تعميرات مكانيك خودرو در كرمانشاه انجام شده است و نشان داد كه بيشترين شيوع اختلالات اسكلتى - عضلانى مرتبط با كار مربوط به يشت و كمر بود و بين كمر درد و ساعت كار

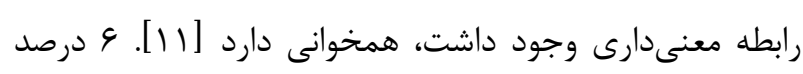
افراد مورد يزوهش در مورد سطح ريسك اندام راست بدنشان در سطح يائين، צادرصد در سطح متوسط، بسادرصد در سطح بالا و rادرصد در سطح خيلى بالا قرار داشتند كه با نتايج مطالعات ميرى و همكاران كه ه درصد در سطح پيائين،

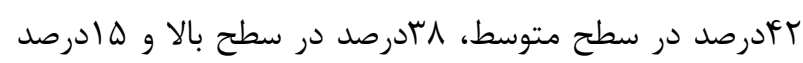
در سطح خيلى بالا قرار داشت هم خوانى دارد [^]. بين سن

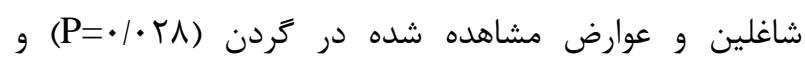

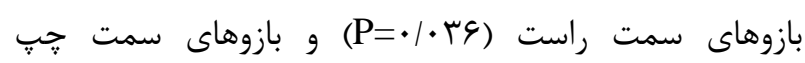

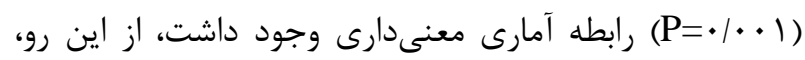

\begin{tabular}{|c|c|c|}
\hline \multicolumn{2}{|c|}{ (درصد) تعداد } & \multirow{2}{*}{ ناراحتى } \\
\hline ندارد & دارد & \\
\hline$\Delta \Gamma(\Lambda \mid / Q F)$ & $\mid r(\mid N / F \varepsilon)$ & كردن \\
\hline 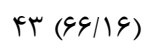 & $r \quad(r T / \Lambda F)$ & شانه \\
\hline$r V(\Delta \mathcal{Q} / q T)$ & $Y \Lambda(F \Psi / V)$ & مجج دست \\
\hline$r \cdot(\{q / \mid \Delta)$ & $r \Delta(\Delta \Gamma / \wedge \Delta)$ & كمر \\
\hline$F V(V T / \mu \cdot)$ & $\|(Y V / V \cdot)$ & ساق ֶٍ \\
\hline
\end{tabular}

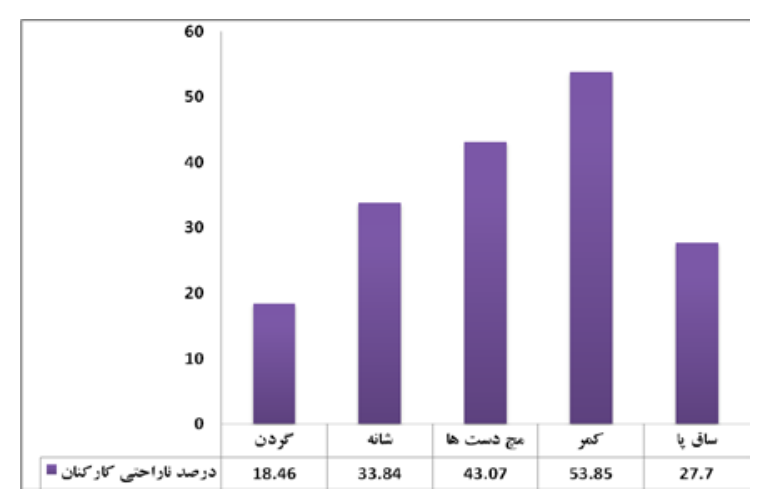

نمودار 1 : توزيع فراوانى ناراحتى اسكلتى - عضلانى در افراد مورد مطالعه جدول ؟: توزيع فراوانى سطوح REBA براى اندام هاى راست افراد مورد مطالعه

\begin{tabular}{|c|c|}
\hline (درصد) تعداد & سطح REBA \\
\hline · & قابل جشم يوشى \\
\hline$q(9 / r \Delta)$ & يائين \\
\hline$r \cdot(\varphi q / \mid Q)$ & متوسط \\
\hline$T I(T r / T \cdot)$ & بالا \\
\hline$\Lambda(I T / \Gamma \cdot)$ & خيلى بالا \\
\hline$\varepsilon \Delta(1 \cdots)$ & جمع \\
\hline \multicolumn{2}{|c|}{ جدول f: توزيع فراوانى سطوح REBA براى اندام هاى جٍ افراد مورد } \\
\hline (درصد) تعداد & سطح REBA \\
\hline - & قابل جشم يوشى \\
\hline$r(\mathcal{F} / \xi T)$ & يائين \\
\hline $\operatorname{pr}(\xi \mathcal{G}|q|)$ & متوسط \\
\hline $\operatorname{IV}(Y \xi|| Q)$ & بالا \\
\hline$r(\mathcal{F} / G T)$ & خيلى بالا \\
\hline $90(1 \cdots)$ & جمع \\
\hline
\end{tabular}


بدون ابزار طراحى شده اركونوميك، عدم وقفه كافى براى

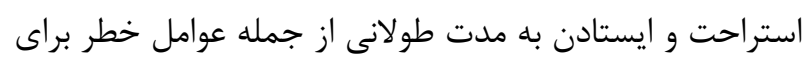

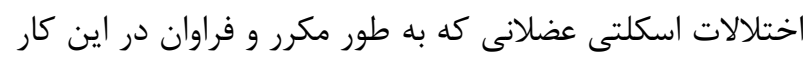

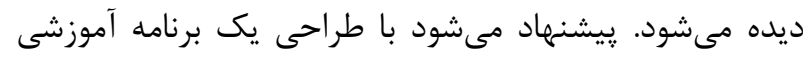

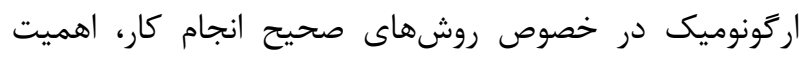

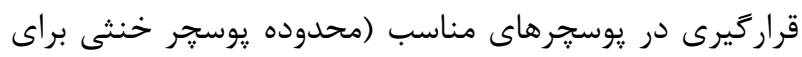

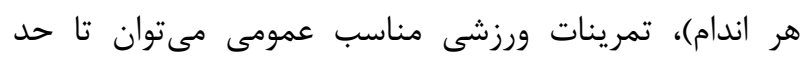
زيادى از استرسهاى ايجادشده در تعميركاران پيشگَيرى نمود.

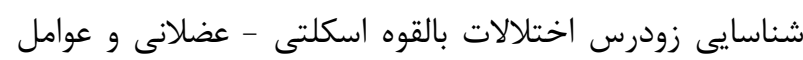

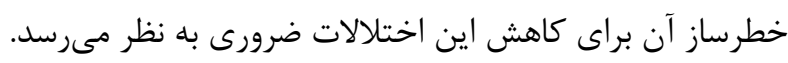

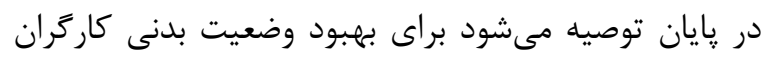
به هنكام كار، كاهش صدمات سيستم اسكلتى - عضلانى و نيز كاهش غيبت از كار، اقدامات اصلاحى اركونوميك انجام

شاغلين بايستى، داراى يوسجر مناسب در ناحيه كمر، مج و

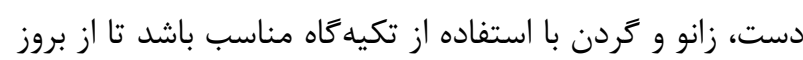

$$
\text { درد در اندامهاى دركير ييشخيرى شود. }
$$

نويسندًان مقاله مراتب سياس و تشكر خوالى خود را از كليه

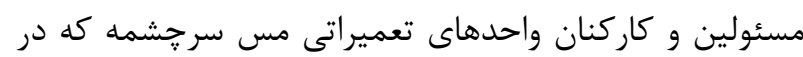

$$
\text { اين يزوهش همكارى داشتند، ابراز مى دارند. }
$$

1. Smith DR, Sato $M$, Miyajima $T$, et al. "Musculoskeletal Disorders Self-Reported by Female Nursing Students in Central Japan: A Complete Cross-Sectional Survey." Int J Nurs Stud. 2003; 40(7): 725-29.

2. Maul A, Laubli T, Klipston A, et al. "Course of Low Back Pain Among Nurses: A Longitudinal Study Across Eight Years". Occup Environ Med. 2003; 60(7): 497-503.
بيماران با سن بالا، درد بيشترى را احساس مى كنند كه با نتايج

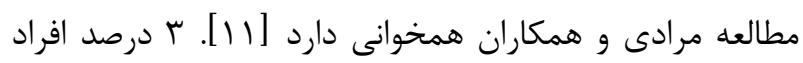

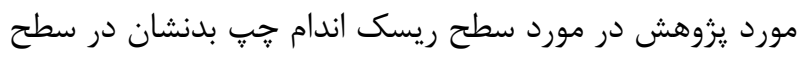

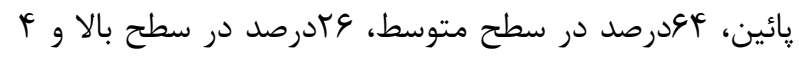
درصد در سطح خيلى بالا قرار داشتند كه با نتايج مطالعات

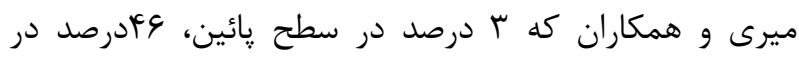

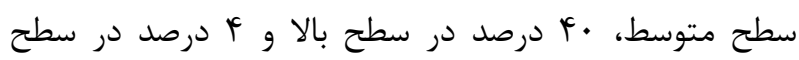

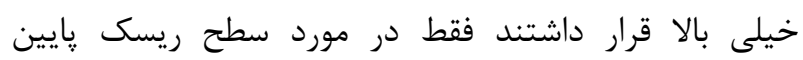

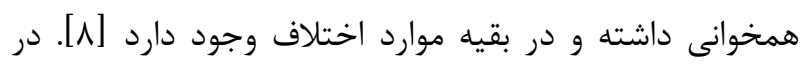

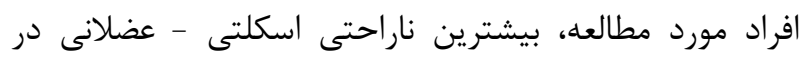
طول سال كذشته مربوط به ناحيه كمر بوده است كه با نتايج

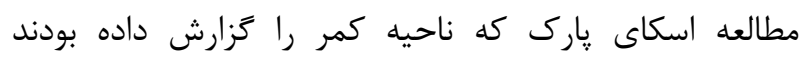

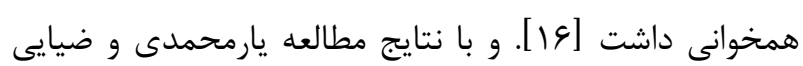
كه بيشترين ميزان ناراحتى در نواحى يشت و كمر بود، مطابقت

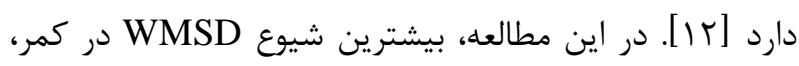

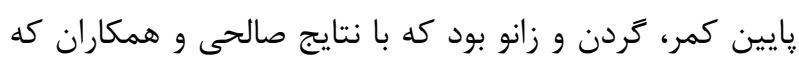
بيشترين شيوع را در همين نواحى كزارش كرده بودند، مطابقت

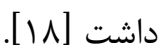

$$
\text { نتيجه }
$$

مطابق يافتهاى مطالعه حاضر مشاهده مىشود، وضعيت

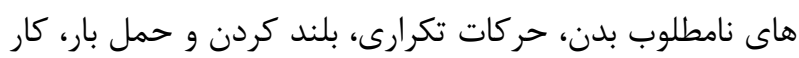

\section{منابع}

3. AghiliNejad M, Farshad AA, Mostafaei M, et al. Occupational Medicine Practice, Arjmand Press 2001. [Persian]

4. Hokmabadi R, Halvani GH, Fallah $\mathrm{H}$. Ergonomic Princiles Decuple, Asar Sobhan Press 2010. [Persian]

5. Seraji J, Sadeghian F, Majdzadeh S. "Epidemiologic study of disease-related absenteeism, with special attention to the 
absence of back pain in coal mine workers. Journal of General Health". 2003; 1(3). [Persian]

6. Kee D, Karwowski W. "LUBA: An Assessment Technique for Postural Loading on the Upper Body Based on Joint Motion Discomfort and Maximum Holding Time". Appl Ergo. 2001; 32(4): 357-66.

7. Mirmohamadi M, Nasl Seraji J, Shahtaheri J, et al. "Evaluation of Risk Factors Causing Musculoskeletal Disorders Using QEC Method in a Furniture Producing Unite,Iranian". J Publ Health. 2007; 33: 24-27. [Persian]

8. Miri M, Hossini $M$, Sharif zade GHR. "Evalution of Ergonomic Postures Of Hairdressers By REBA (Rapid Entire Body Assessment) In Iran". Journal of Ghonabad university of medical sciences. 2008; 14(2): 3944. [Persian]

9. Mirhosseini Z, Gholizadeh N. "Determining the physical damage caused by work in terms of ergonomic principles among librarians of public libraries in the city of Isfahan". Knowledge Science. 2010; 3(11): 117-133 [Persian].

10. Yaghobee S, Esmaeili V. "Evaluation of the effect of the ergonomic principles' instructions on the dental students' postures; an ergonomic assessment". Journal of Dental Medicine-Tehran University of Medical Sciences. 2010; 23(2): 121-127. [Persian]

11. Moradi M, Poursadeghiyan M, Khammar A, et al. "REBA method for the ergonomic risk assessment of auto mechanics postural stress caused by working conditions in Kermanshah". Ann Trop med Publ Health. 2017; 10(3): 589-94. [Persian]

12. Yarmohammadi H, Ziaei M, et al. "Evaluation of Occupational Risk Assessment of Manual Load Carrying Using KIM Method on Auto Mechanics in Kermanshah City in 2015". Research Journal of Medical Sciences. 2016; 10(3): 116-119. [Persian]

13. Hignett S, Atamney MC. "Rapid Entire Body Assessment (REBA)". Applied Ergonomics. 2000: 31(2): 201-5.

14. Saremi, M. Evaluation of musculoskeletal disorders in dentists of Shahed University. 2003. Online. Available at: URL:http://dbase.irandoc.ac.ir/00668/00668505. htm.

15. Abdoli Eramaki M. Occupational biomechanics \& design of workplace (ergonomic), 1st ed. Tehran: Omid Majed Publisher; 1999.

16. Park SK, Choi YJ, Moon DH, et al. "Work Related Musculoskeletal Disorders of Hairdresser". Korean J Occup Environ Med. 2000; 3(12): 395-404.

17. Hejazi Ma, Tamaddon J, Gholami A. Evaluation of ergonomic risk by REBA method and its relation with musculoskeletal disorders in the staff of Gonabad brick burner furnaces in 2011. Persian Ahwaz, Iran; Feb 16-19, 2014. [Persian]

18. Salehi Sahlabadi A, Naslseraji J, Zerati H, et al. "Curves of the cervical spine, back and lumbar 
تعيين ميزان شيوع آسيبهاى اسكلتى - عضلانى ....

spine with the prevalence of musculoskeletal disorders". J Sch Public Health Inst Public
ياسر صحر انورد و همكاران

Health Res. 2009; 6: 49-60. [Persian] 


\title{
Determining the prevalence of musculoskeletal injuries and its relationship with workplace posture in copper industry repairmen
}

\author{
Masuomeh KARAMI ${ }^{1}$, Saeid Ghane EZABADI ${ }^{2}$, Zohreh KARAMI $^{3}$, Yaser SAHRANAVARD ${ }^{4}$
}

\section{Abstract}

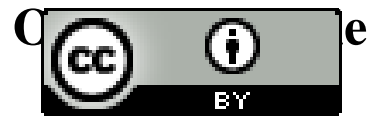

Received: 2017/12/23

Accepted: 2018/04/04

\section{Citation:}

KARAMI M, EZABADI

SG, KARAMI Z,

SAHRANAVARD Y.

Determining the

prevalence of

musculoskeletal injuries

and its relationship with

workplace posture in

copper industry

repairmen. Occupational

Hygiene and Health

Promotion 2021; 5(3):

243-250.

Introduction: Musculoskeletal disorders are one of the most common causes of occupational injuries that mainly affect the low back, neck, and upper limbs. Preventing these discomforts requires assessing workplace posture using ergonomic job analysis methods. The aim of this study was to determine the rate of musculoskeletal injuries of mechanical repairs using REBA method in 2018 in Sarcheshmeh copper mine.

Methods: In this descriptive-analytical study, the workplace posture of 65 mechanical repairs were evaluated using REBA method. The prevalence of musculoskeletal disorders was also obtained using the Nordic questionnaire. The collected data were analyzed by SPSS 20 .

Results: In this study, the prevalence of wrist discomfort was $43.07 \%$, neck $18.46 \%$, shoulder $33.84 \%$, low back $53.85 \%$, and leg $27.70 \%$. Regarding the risk level of the right limb, 9.25\% of the subjects were at a low level, $46.15 \%$ at a medium level, $32.30 \%$ at a high level, and $12.30 \%$ at a very high level. Also, regarding the risk level of the left limb, $4.62 \%$ of the subjects were at a low level, $64.61 \%$ at a medium level, $26.15 \%$ at a high level, and $4.62 \%$ at a very high level.

Conclusion: These results indicated that the workplace posture of the subjects needed to be improved. To prevent the occurrence of these disorders, education is required to recognize biomechanical risk factors and correct methods of working, use of appropriate tools and appropriate to the work process, and improvement and control of stressors and environmental factors.

Keywords: Ergonomic Assessment, Body Posture, Mechanical Repairs, REBA Method

\footnotetext{
${ }^{1}$ Department of Occupational Health Safety, School of Health, Sirjan University of Medical Sciences, Sirjan, Iran (? ${ }^{2}$ Department of Occupational Health Engineering, School of Health, Tehran University of Medical Sciences, Tehran, Iran 6

${ }^{3}$ Department of Ergonomics, School of Health, Tehran University of Medical Sciences, Tehran, Iran $(C$

${ }^{4}$ Occupational health of copper in Kerman region, Sarcheshmeh, Kerman, Iran

*( Corresponding author: yaser.Sahranavard@yahoo.com)
} 
